\title{
Analysis of Student Perceptions and Behaviors in a Flipped Classroom Un- dergraduate Information Technology Course
}

Mr. Rob Elliott, Purdue University School of Engineering and Technology, Indiana University Purdue University at Indianapolis

Rob Elliott is a Lecturer of Computer and Information Technology at Indiana University Purdue University at Indianapolis. As a web and mobile application developer with nearly two decades of experience, he creates solutions for organizations of all sizes. Rob attempts to integrate his real-world experiences (both good and bad) into the classroom environment whenever possible. His teaching style focuses on problem solving, experiential learning, iterative development, and letting students "get their hands dirty." 


\section{Analysis of Student Perceptions and Behaviors in a Flipped Classroom Undergraduate Information Technology Course}

\section{Introduction}

The flipped classroom pedagogy has become quite prevalent in the higher education community in recent years. Technical advances combined with increased student comfort in an online learning environment have afforded a wide range of opportunities to infuse recorded course materials and automated assessment into a traditional classroom-based course. In short the flipped classroom asks students to interact with course material prior to coming to the classroom so that face-to-face time can be used for active learning ${ }^{[1,2]}$. Flipping provides students earlier exposure to course topics in order to give them a common vocabulary and fundamental knowledge to be immediately applied in inquiry-based learning activities.

This study describes the student attitudes of the flipped classroom, as measured by anonymous survey data collected at the start, midpoint, and end of the semester. The course examined in the study is a sophomore-level computer systems analysis and design from the fall semester of 2013. When appropriate, comparisons will be made to a non-flipped section of the same course from Fall 2012.

The purpose of the study is to determine if the flipped classroom structure is acceptable to students, and to discover student opinions about the pedagogy. The author wished to understand any flaws in the flipped classroom implementation and determine if the process was in any way detrimental to the learning experience. As the results demonstrate, students were initially hesitant but open-minded about the flipped classroom experience, and in the end showed a noticeable appreciation for the modified course layout.

\section{Choosing the Flipped Classroom}

Prior to the study, the author participated in a faculty learning community (FLC) that researched the implementation of the flipped classroom. This discovery process revealed that there is no set definition of a "flipped" classroom and no specific outcomes that must be met in order to consider a class "flipped." However, a commonly accepted notion of the flipped classroom is that it is result of an involved process that does more than simply rearrange the course schedule. Flipping combines a number of teaching methods and builds on theories such as student-centered learning, constructivism, problem-based learning, and peer assisted learning ${ }^{[3]}$.

There are a number of reasons why a flipped classroom might be considered. In the ongoing struggle of offering breadth vs. depth in the classroom the flipped classroom could seem like a means of increasing the amount of material that can be introduced in a single course. Some instructors may choose to flip as a means of validating that students read or viewed required 
information. Another motivation might be an attempt to improve grades in a course with the use of active-learning techniques ${ }^{[4]}$; moving content consumption outside of the classroom gives more time for hands-on learning. Finally, some courses are flipped so that more collaborative or peer learning can take place, allowing students to have some scheduled work time without haggling over other meeting arrangements. Just as there are no set rules that define a flipped classroom there is no standard justification that must be met in order to perform a flip.

The author investigated a flipped classroom pedagogy for this particular computer systems analysis and design course for a variety of reasons. The average student grade in the course has been quite high in the past, but it was the opinion of the author that the class could still be improved with more interactive and collaborative work. A similar flipped classroom implemented by Gannod, Burge, and Helmick at Miami University indicated that the educational model might go hand-in-hand with the concepts of software engineering ${ }^{[5]}$. First, a large amount of terminology and rote memorization is required in this course as the students are taught how to describe systems using standardized language and models. This type of learning can easily be done independently through the use of learning activities. Another consideration is that the course focuses on iterative and incremental improvement in the proposed software models. Review, revision, and improvement are key components of any modeling process and are difficult to accomplish within the confines of a single weekly deliverable. Finally, the most invigorating element of this flipped course is the abundance of class time it provided for collaborative activities and peer learning, which is reflective of how the systems analysis and design process is conducted in a real world environment. The development of a rich classroom environment was a fundamental goal of the author's flipped classroom ${ }^{[6]}$.

\section{Course Details and Student Demographics}

The systems analysis and design course is a core requirement of students studying computer technology and focuses primarily on the makeup of software systems. The subject matter builds on the concepts of logic, decomposition, and problem solving introduced in the first year. The course was held during a typical 16-week semester and met on Monday and Wednesday mornings for 75 minutes at a time.

The course itself is made up of a number of learning modules, most of which are scheduled for a single calendar week although there are a few longer topics. 10 distinct learning modules were scheduled over the first 12 weeks of the course. Students are engaged in two larger, multideliverable final projects during the last four weeks of the course.

Of the 27 students in the systems analysis and design course, 26 (96.3\%) are computer technology (CIT) undergraduates. One other student is pursuing an undergraduate certificate in CIT for which this course is also required. The students in the course represent all of the four concentrations available to undergraduates in the CIT program. 
The students appear to be technologically savvy. $100 \%$ reported having high-speed internet access at their residence, whether off-campus or in student housing. 24 students (88.9\%) had taken at least one " $100 \%$ online" course, and 16 students (59.3\%) reported being active on social media platforms which could indicate some measure of comfort with working with online resources.

The mechanics of the flipped classroom seemed feasible based on the student's technological background and experience working outside of the traditional classroom structure. The majority of students $(85.2 \%)$ reported that they did the majority of their schoolwork from home, and only five students (18.5\%) reported that they had heard of the flipped classroom concept.

\section{Methodology}

Students were introduced to the concept of the flipped classroom and were informed in advance of the nature of the study. The pre-recorded lectures that were provided to the students were hosted in a software system called Echo360, which allowed the instructor to monitor the viewing habits of individual students. Other software used for collaboration in the course included the Oncourse (Sakai) course management system, text and spreadsheet documents shared using Google Apps, and LucidChart, a collaborative diagramming software tool.

Four anonymous surveys were distributed to students during the semester. The first was introduced at the beginning of the first session of the course, prior to any introduction to the subject or the flipped classroom concept. The second was given during the first week of the course but after the students had been informed of the flipped classroom and the study. The third and fourth surveys were distributed at the midterm and end of the semester, respectively. Anonymity in the surveys was important to the author so that students could freely give their opinions about the flipped classroom pedagogy. 27 students participated in the course, although that number might vary in individual data points as described below.

\section{Implementing the Flipped Classroom}

At a minimum the flipped classroom entails three key components: content consumption outside of the classroom, some form of assessment to gauge the completion of that content consumption, and then a variety of classroom activities and assessments to validate the course materials are understood.

Many flipped classrooms use the formative assessment with a carrot and stick approach ${ }^{[7,8]}$; students consume the course materials because they know they will be graded on whether or not they have done so. The author rejected this model somewhat and instead chose to use the formative assessment as an opportunity for students to produce a rough draft of some key 
deliverable to be discussed during class time. Interim assessments, which consisted of a variety of think-pair-share, small group, and collaborative exercises, allowed the students to revise and improve on the work done in the formative assessment. All of the work done throughout the week was then material that could be applied to the summative assessment due at the conclusion of the week's learning module.

Thus, the author intended to create a constructivist environment that invoked problem-based learning. Savery and Duffy ${ }^{[9]}$ state that " $[t]$ he teacher must assume the roles of consultant and coach," and it was the author's opinion that this could best be accomplished with the use of the flipped classroom methodology.

In order to effect the changes noted, the flipped course was built with the following four guiding principles in mind:

1. Make it Fair to the Students

2. Balance the Course with Formative, Interim, and Summative Assessments

3. Make it Engaging for the Students

4. Focus on Outcomes, not on Inputs

A discussion of each goal and its impact on student satisfaction with the course follows below.

\section{Principle 1: Make it Fair to the Students}

The nature of the flipped classroom "front loads" some of the week's work onto the students. The study course met on Monday morning, and students were expected to come to class prepared to engage in an active learning activity. Because of this the course schedule was shifted away from a traditional week so that the two class meetings actually fell in the middle of the learning module.

It was the opinion of the author that the non-traditional schedule would be the key to successful implementation of the flipped classroom, but was also assumed to be the biggest hurdle for the students to overcome. The author's experience has been that students are quite reluctant to follow a schedule that varied from their other courses and in the past had been resistant to a change in the thinking that "a week starts on Monday and ends on Sunday." However, the schedule shift was unavoidable in order to give the students adequate preparation time and the flipped classroom.

Simply put, the students had to see that the schedule change was to their benefit. As part of the introduction to the flipped classroom pedagogy the students were shown how the schedule would shift from the traditional layout to the new format. The students were also shown how the distribution of their grade would also change so that the effort they made in preparation 
(formative assessments) and classroom work (interim assessments) would be rewarded, and how the reduction of impact of "homework" (summative assessments) would relieve some of the mental burden of larger assignments. The traditional course schedule and grade distribution is demonstrated in

Figure 1 below. The revised schedule and distribution is provided in

Figure 2.

\begin{tabular}{|l|l|l|l|l|l|}
\cline { 2 - 6 } & \multicolumn{1}{|c|}{ Mon } & Tues & Wed & $\begin{array}{c}\text { Thurs - Sun } \\
\text { Sat }\end{array}$ & \multicolumn{1}{|c|}{} \\
\hline In Class & Lecture & & $\begin{array}{l}\text { Exercise/ Quiz } \\
\text { (Interim } \\
\text { Assessment) }\end{array}$ & & $\begin{array}{l}\text { Homework } \\
\text { (Summative } \\
\text { Assessment) } \\
\text { Oue }\end{array}$ \\
\hline $\begin{array}{l}\text { Percentage of } \\
\text { Final Grade }\end{array}$ & & & & Due \\
\hline
\end{tabular}

Figure 1: Traditional Classroom Schedule (Non-Flipped) 


\begin{tabular}{|c|c|c|c|c|c|}
\hline & $\begin{array}{c}\text { Fri } \\
- \\
\text { Sun }\end{array}$ & Mon & Tues & Wed & Thurs \\
\hline In Class & & $\begin{array}{l}\text { Active } \\
\text { Learning } \\
\text { (Interim } \\
\text { Assessment) }\end{array}$ & & $\begin{array}{l}\text { Active } \\
\text { Learning } \\
\text { (Interim } \\
\text { Assessment) }\end{array}$ & \\
\hline Out of Class & $\begin{array}{l}\text { Lecture / } \\
\text { Reading } \\
\text { (Formative } \\
\text { Assessment) }\end{array}$ & & & & $\begin{array}{l}\text { Homework } \\
\text { (Summative } \\
\text { Assessment) } \\
\text { Due }\end{array}$ \\
\hline $\begin{array}{l}\text { Percentage of } \\
\text { Final Grade }\end{array}$ & \multicolumn{4}{|c|}{$35-40 \%$} & $60-65 \%$ \\
\hline
\end{tabular}

Figure 2: Flipped Classroom Schedule

At the conclusion of the semester, students were asked simply "With the flipped classroom structure, did you feel that the Thursday night homework due date was fair or unfair?" As demonstrated in Figure 3 below students reported a good deal of satisfaction (81\%) with the Thursday night due date for summative assessments. Anecdotally, two students reported that the Thursday night deadline was difficult because of their work schedules. This was significant to the author, as students tend to plan their schedules to free up weekends for homework. Because the schedule of the flipped classroom is so different from that of other courses, students may have a more difficult time scheduling a wider range of deadlines. 


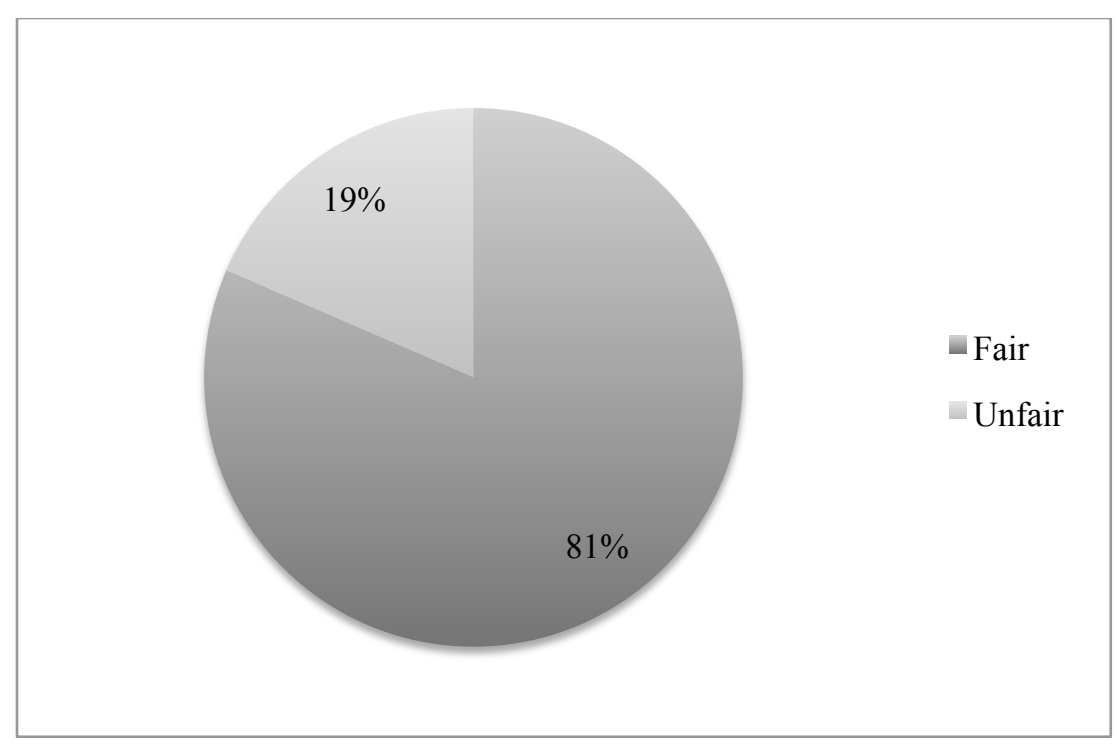

Figure 3: Student Opinion of the Flipped Classroom Schedule (n=27)

\section{Principle 2: Balance the course with Formative, Interim, and Summative assessments}

In prior iterations of the study course a good deal of time was spent introducing and reviewing fundamental concepts during face-to-face time. This included vocabulary introduction and reviews, sample diagrams and notations, and traditional lectures that introduced the procedures the students would perform to produce their deliverables. The bulk of the students' hands-on work was done in the form of summative assessments (i.e. "homework"), which made up the majority of the students' grade in the course.

As stated earlier, a key component of this particular course is the investigation of a problem and the development of a solution for that issue. In this instance the solutions are computer systems that tackle some sort of business need. Those familiar with constructivist learning methods would recognize these systems as complex problems that must be solved. The students are instructed that these systems are built using a repetitive process, and the software development lifecycle - whichever model is in use - depends upon continual revision. However, this designtest-improve model is hardly confined to the computer technology realm. A similar process is invoked in the any number of lines of study, including the development of compositions (either creative writing or technical documentation), scientific experiments, and engineering diagrams, to name a few.

Because the concept of iterative and incremental improvement is so fundamental to this course in particular, the author chose to include that methodology directly into the mechanism of the classroom. The flipped classroom provided the perfect opportunity to allow students to make a first attempt at a solution, compare and revise the answers, and then finalize their work and apply any additional discovery to be submitted at the end of the course topic. 
As discussed, the author's flipped classroom took a slightly different approach than what has been reported by others. The deliverable for each learning module was broken up into formative (preparatory), interim (class time), and summative (homework) assessments. By infusing a single deliverable throughout a variety of assessments over the learning module, the students had the opportunity to engage with the course material in such a way that comparison, revision, and improvement became a part of the coursework process. This metacognitive approach afforded the students the opportunity to revise, improve, and provide cooperative support with fellow students each step of the way. Assessment distribution for a typical week in the study course is found in

Figure 4.

\begin{tabular}{|l|c|c|c|}
\cline { 2 - 4 } \multicolumn{1}{c|}{} & $\begin{array}{c}\text { Formative } \\
\text { Assessment }\end{array}$ & Interim Assessments & $\begin{array}{c}\text { Summative } \\
\text { Assessment }\end{array}$ \\
\hline In Class & 5 points & 2 @ points each & \\
\hline Out of Class & $\mathbf{1 2 . 5 \%}$ & $\mathbf{2 5 \%}$ & 25 points \\
\hline $\begin{array}{l}\text { Percentage of } \\
\text { Week's Grade }\end{array}$ & & $\mathbf{6 2 . 5 \%}$ \\
\hline
\end{tabular}

Figure 4: Assessment Distribution for Typical Flipped Classroom Learning Module

This technique presented a significant shift in the quantity of assessments given to the students. When compared to the Fall 2012 semester section of the same course (which used the same case studies and deliverables as the study section), there was a significant increase in the number of formative and interim assessments while the number of summative assessments remained relatively stable, as detailed in Figure 5. 


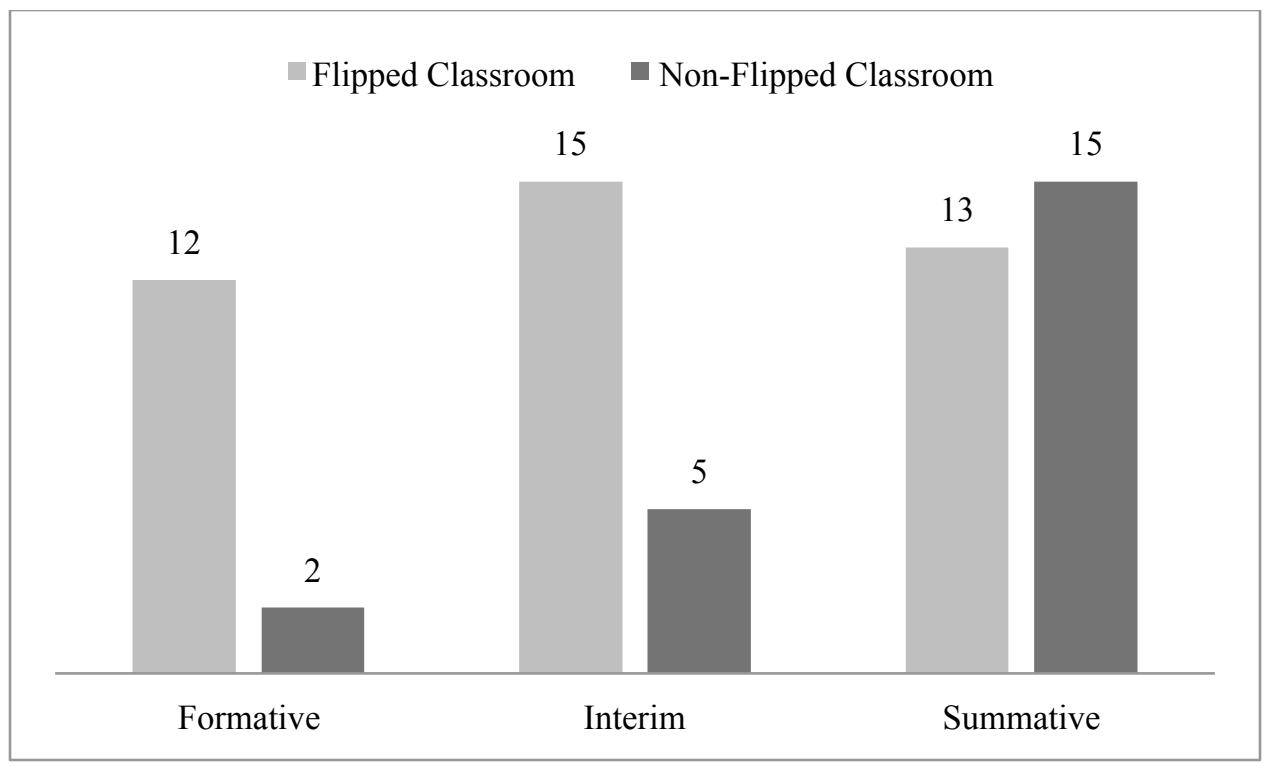

Figure 5: Number of Assessments by Assessment Type

Although the quantity of assessments changed, student grades were still primarily based on work done in summative assessments. Figure 6 shows a comparison of how the increased number of formative and interim assessments was factored into a student's final grade compared to a nonflipped section of the course.

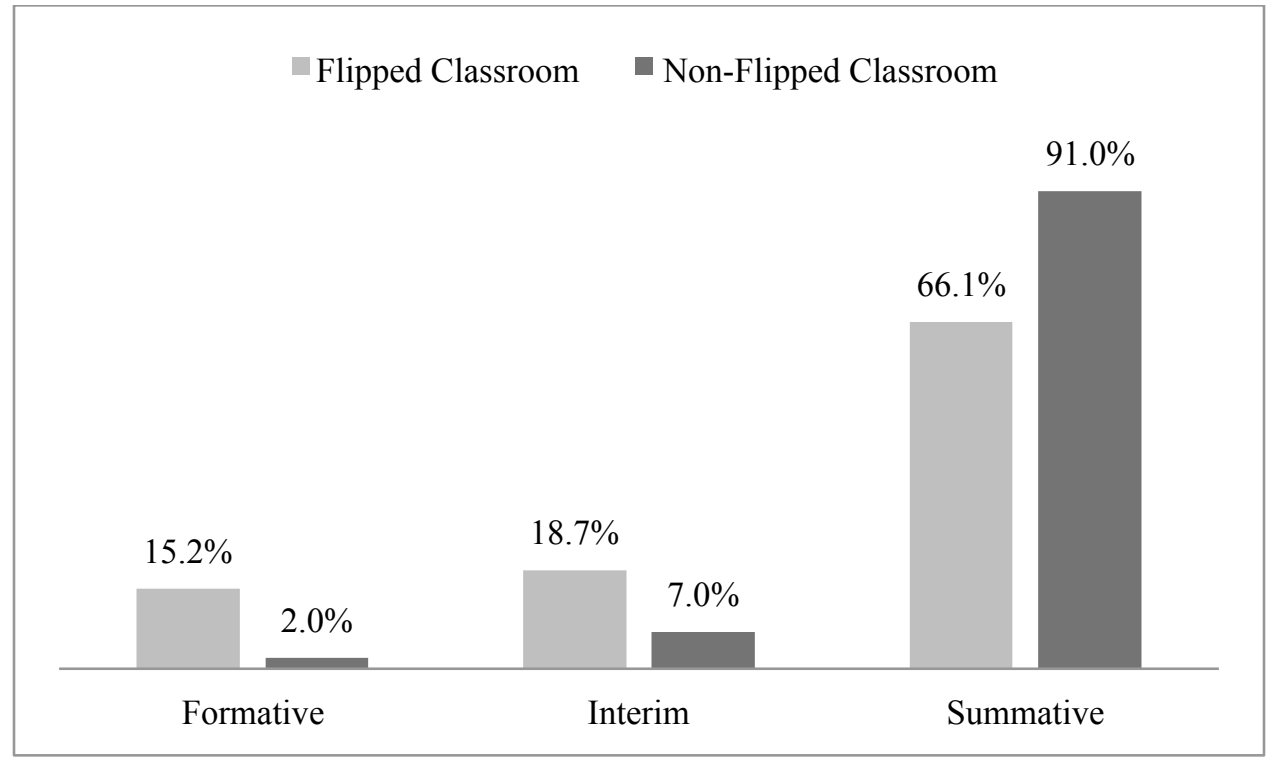

Figure 6: Percentage of Final Grade by Assessment Type

Formative assessments, which students were expected to bring with them to the week's first class meeting, often took the form of a rough draft of a problem statement, a single process diagram, or a list of system components that were to be organized. These formative assessments, worth 
relatively few points, were graded for completion and a high-level content review and were mostly intended to spark conversation and questions.

Interim assessments took place during class time and were the heart of the author's flipped classroom approach. Typically there was one graded assessment per class meeting, although that number varied depending on the needs of the students and the intensity of the week's topic. Initial interim assessments frequently asked students to compare and contrast their solution to the formative assessment with peers in an attempt to improve upon the initial solution, akin to a think-pair-share exercise. Other interim activities involved problem-solving challenges, small group work using collaborative software tools, and delving into additional components of the week's summative assessment. Anecdotally, students particularly enjoyed working on multiple aspects of a single complex problem within small working groups so that it was possible to share common elements of all student solutions in their own summative assessment work.

Summative assessments involved the collection, revision, and dissemination of the work done in the formative and interim assessments. All summative assessments were completed individually, although students were encouraged to review work done during the interim assessments and incorporate that into their deliverable where appropriate. This technique also gave the students the opportunity to revise and, if necessary, reject solutions that they felt were not correct, thus affording them the opportunity to analyze a number of thought processes when composing their own solutions.

Because of the increase in the number of formative and interim assessments from past semesters, the author asked the students about their workload and its impact on their learning. Students were asked if the amounts of prep work, in-class exercises, and homework was "not enough," "just right," or "too much" (Figure 7.) 80-85\% of students reported that the workload for the course was "just right," and 11-18\% of the students expressed the opinion that there were too many assessments.

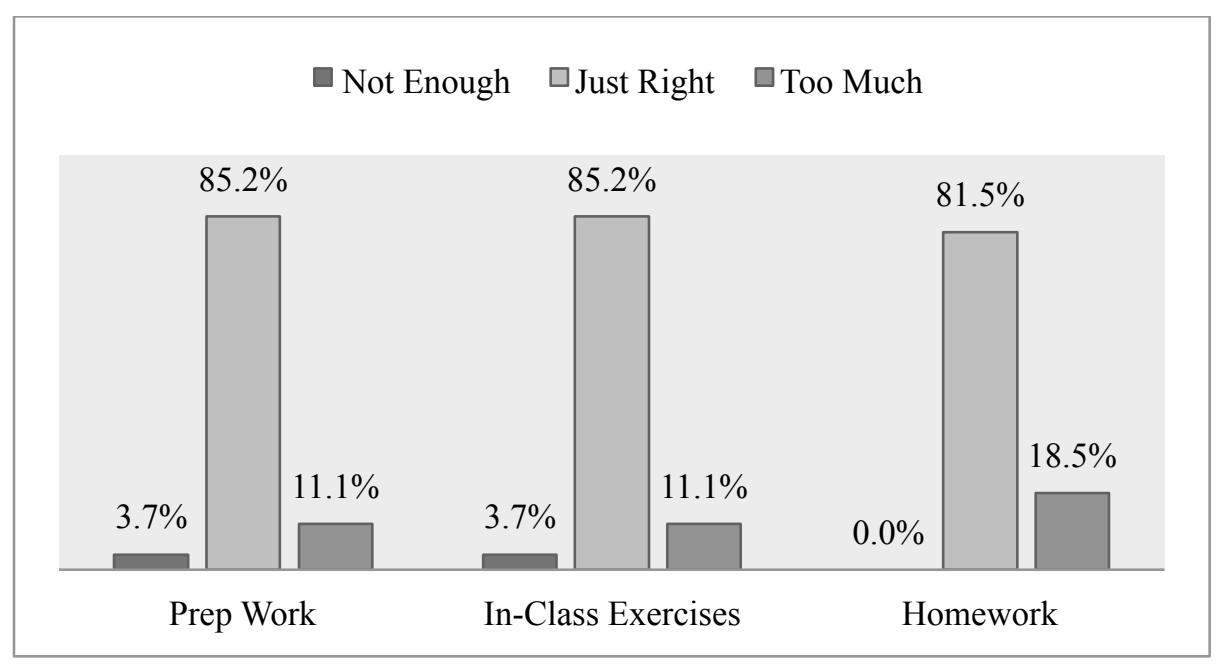

Figure 7: Student Opinion on the Quantity of Assessments ( $n=27)$ 


\section{Principle 3: Make it Engaging for the Students}

Distributing the workload of a single deliverable across multiple assessments appeared to aid in the learning process. Providing students the opportunity to revise their initial attempts made interacting with the course work more practical. In the final survey of students, an open-ended request for feedback provided support for this conclusion. When asked about the flipped classroom pedagogy, one student reported "[i]t seemed as if the only real difference with a flipped classroom [was] less lecture, which is fine with me. Plus the interaction with the group work helps a lot with understanding concepts from other perspectives." Students also reported that the assessments were meaningful; as one student put it: "The work all seemed to have some sort of purpose."

The author asked students to gauge the helpfulness of both the formative and interim assessments. Those results appear in Figure 8 below. Students overwhelmingly reported that the exercises introduced in the flipped classroom section were beneficial to understanding the course material.

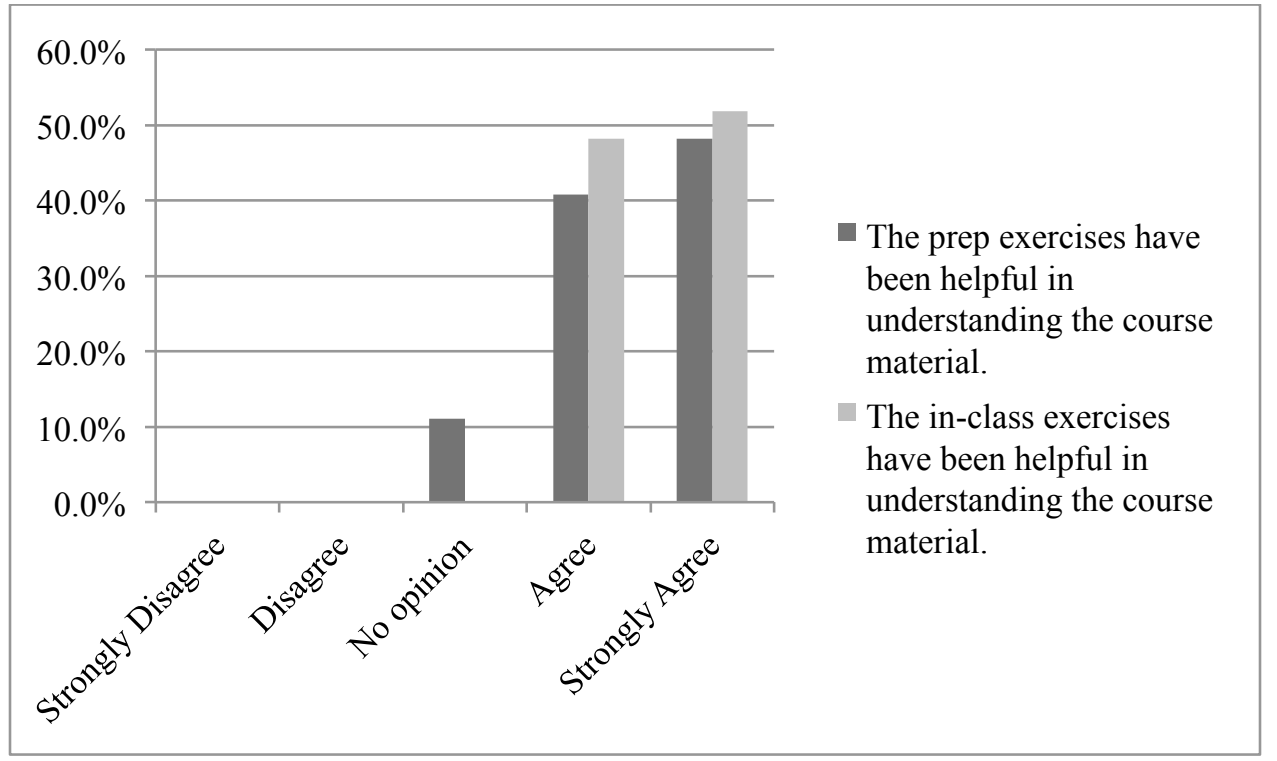

Figure 8: Student Opinion on the Helpfulness of Formative and Interim Assessments (n=27)

Many interim assessments were conducted in teams and small groups. This was a source of some concern to the author at the outset. Although group activities have been shown to be quite effective in constructivist learning environments, students in the classroom sometimes frown upon such collaboration. Students were given a five point likert scale and asked to rate the following two statements:

1. PRIOR to this course I enjoyed collaborating on group assignments.

2. IN THIS COURSE I am enjoying the collaboration on group assignments. 
Students in the flipped classroom displayed a more receptive attitude to collaborative exercises than they have in other courses, as demonstrated in Figure 9.

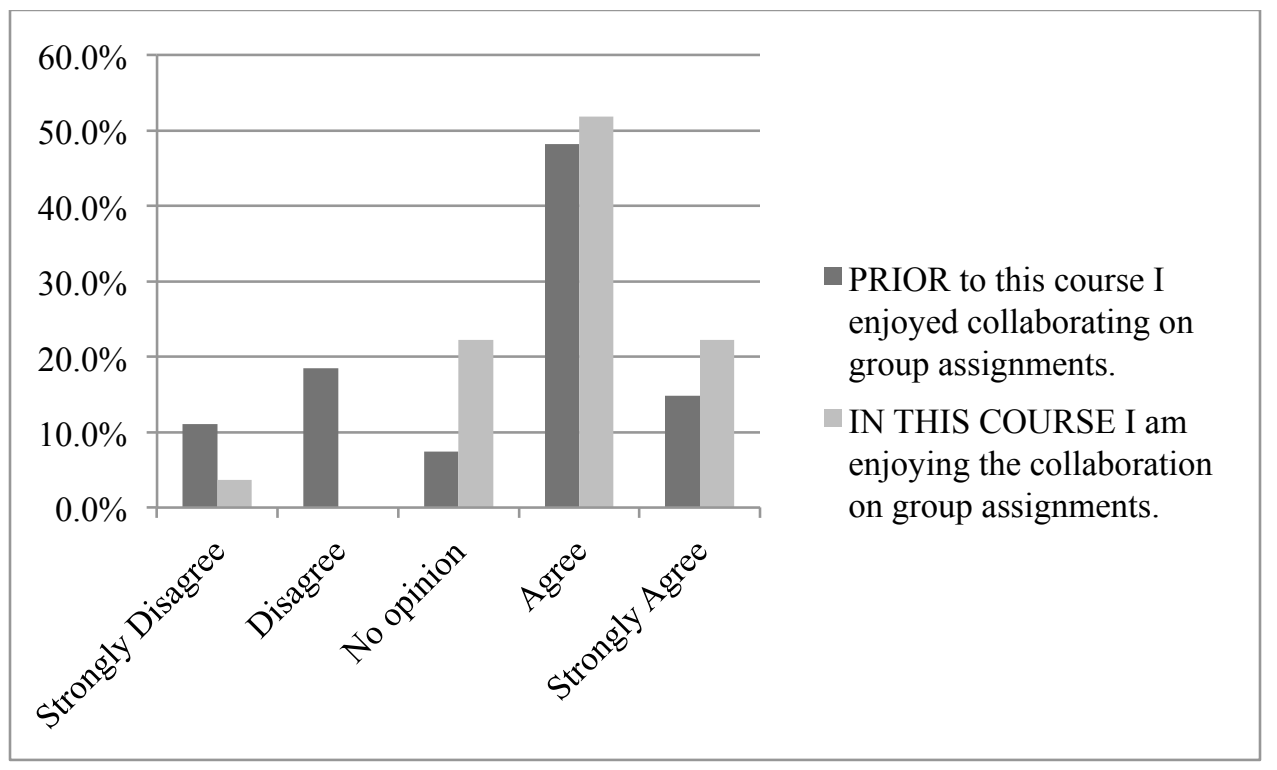

Figure 9: Student Opinion on Group Work in the Flipped Classroom $(n=27)$

Overall it appears that students were satisfactorily engaged with the course materials, and that the increase in assessment quantity and the increased amount of collaborative exercises were well received by students in the flipped classroom.

\section{Principle 4: Focus on Outcomes, not on Inputs}

As stated previously, the each learning module's course materials consisted of 1-2 chapters in a textbook and a number of recorded video lectures that included demonstrations and examples of techniques introduced in the text. The amount of recorded material varied per week, ranging from a minimum of 20 minutes to a maximum of 45 minutes of video. Students were expected to read and review the materials and complete a formative assessment prior to attending the first class session of the week.

Although the Echo360 system that hosted the recorded lectures records specific interactions of students with recording, the reporting statistics of the system were not without error. Because the statistics were unreliable, the author chose not to include them in this study. However, students were asked to report their approximation of how much of the recorded material each had reviewed over the course of the semester. Those statistics appear in Figure 10. 


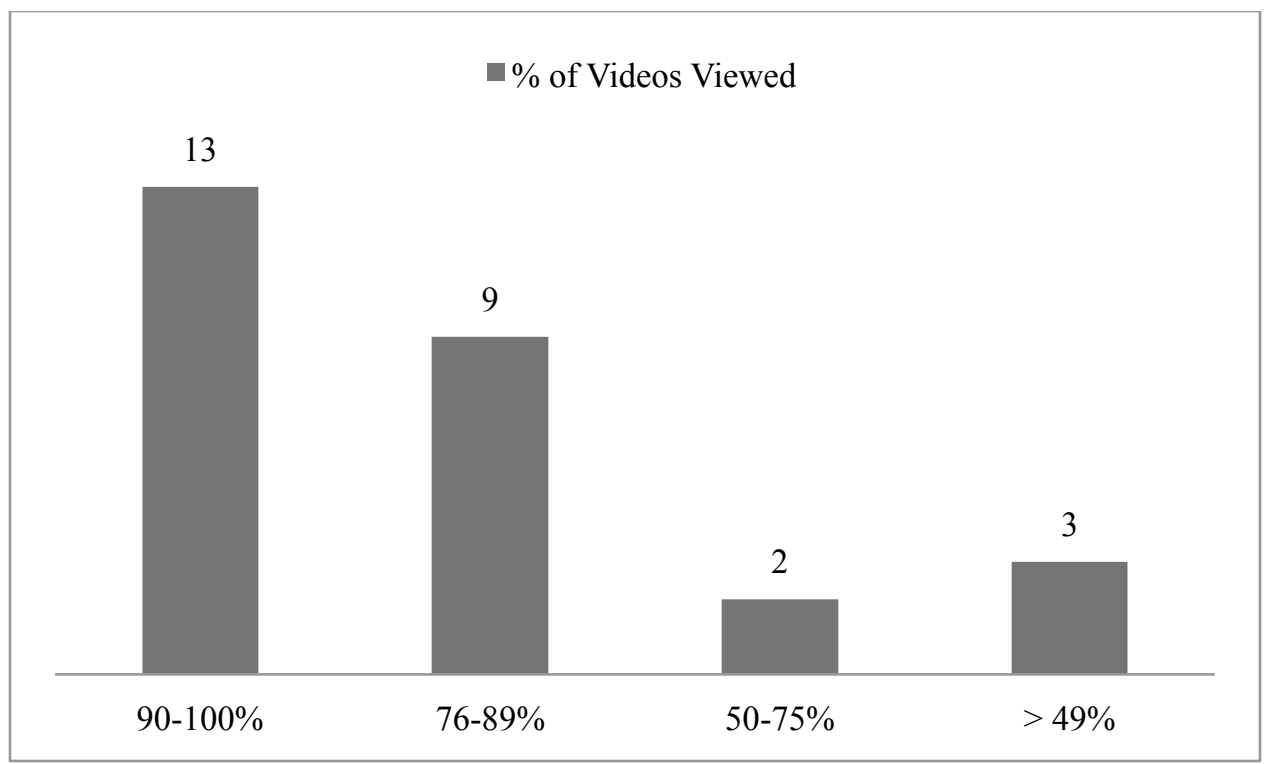

Figure 10: Student Estimate of Percentage of Videos Viewed (n=27)

Students were also asked how much time they spent on each type of preparatory work prior to the first class session of the week. In general students reported spending between four to five hours preparing for class, as demonstrated in Figure 11. (One student's responses were removed due to obvious falsification.)

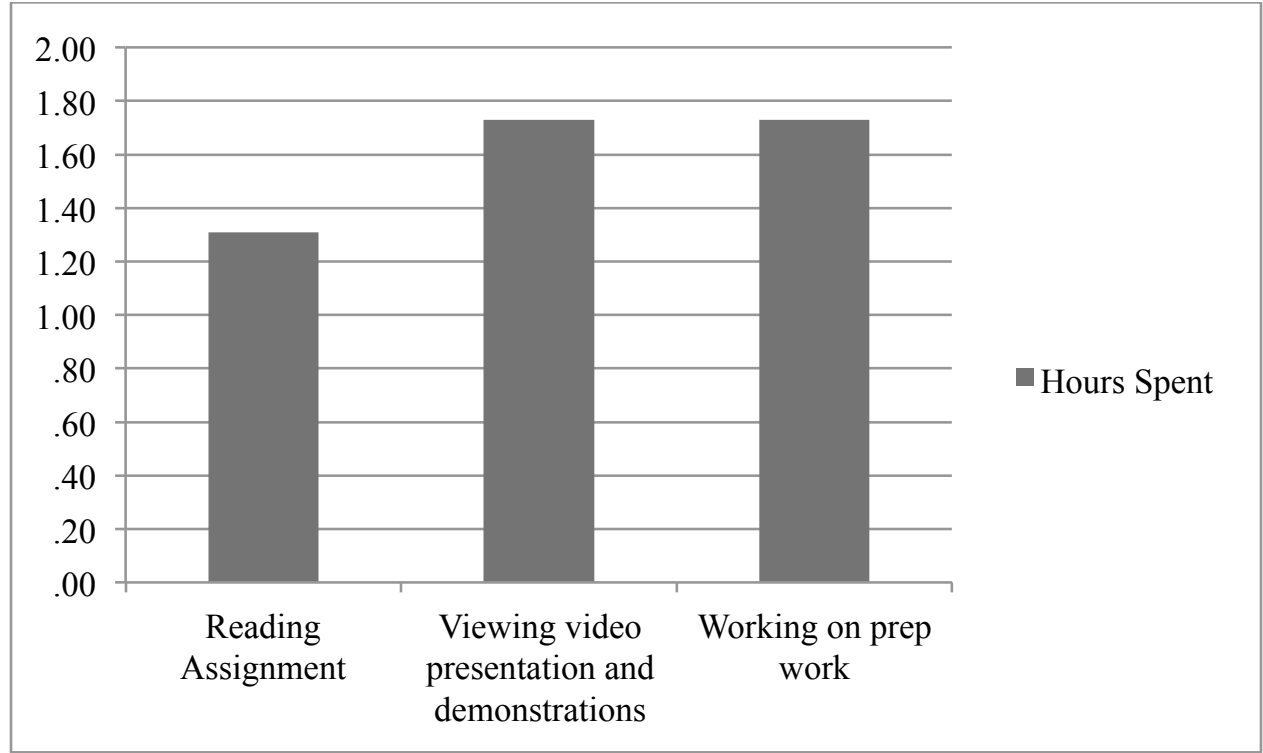

Figure 11: Reported Amount of Time Spent on Preparatory Exercises (n=26)

Finally, students were asked how often, if ever, they reviewed the recorded lectures while working outside of the classroom. Those results appear in Figure 12. 


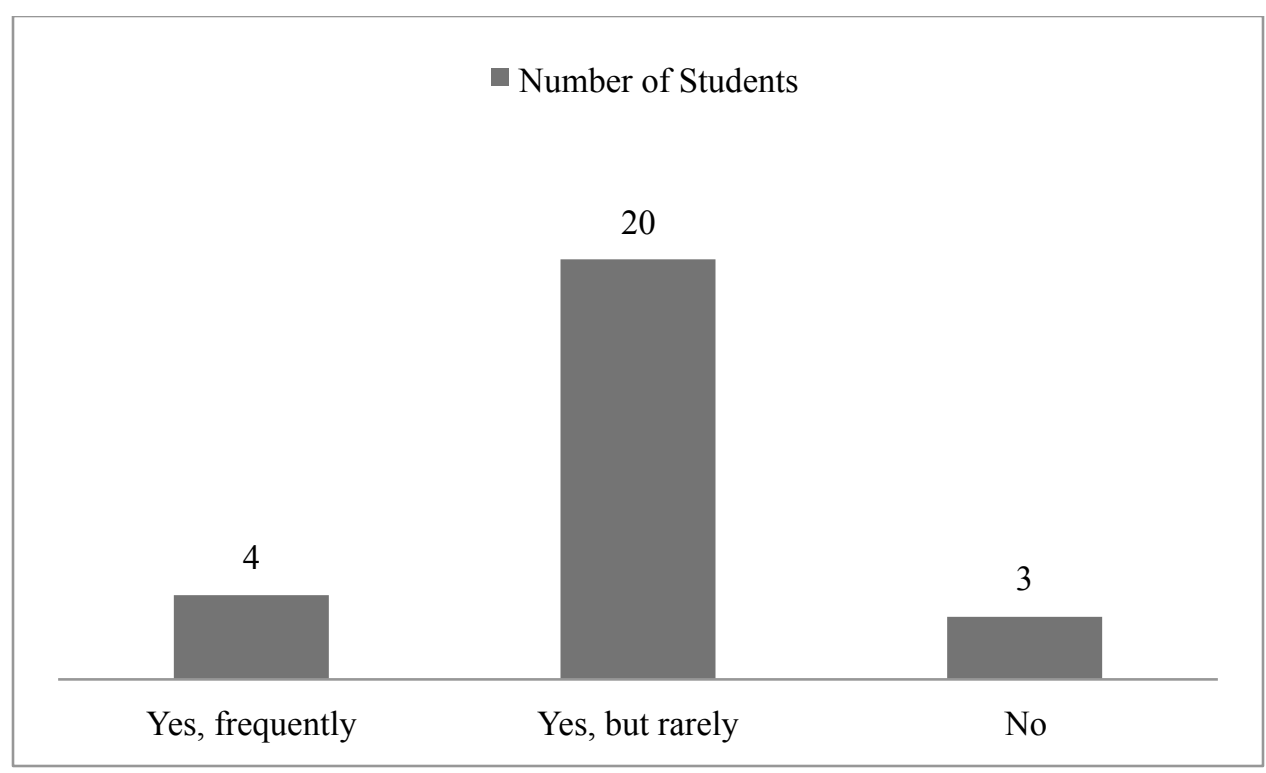

Figure 12: Number of Students Who Reviewed Recorded Lectures a Second or Third Time (n=27)

The fourth guiding principle of the author's flipped classroom was to focus on the outcome of the student assessments rather than expend energy forcing the students to consume course content. Although it is possible to record a student's every interaction with electronic course materials, it is the opinion of the author that this is not necessary. Instead, time was spent creating engaging, indexed, reviewable content that the students could refer to on an as-needed basis. As shown above, over half of the students in the course reported watching less than $90 \%$ of the recorded lectures over the course of the semester - and three students noted that they watched less than $50 \%$. While that is somewhat disheartening to an instructor, the relationship between even the most brilliant lecture and student outcome is tenuous at best. Constructivist learning theories hold that students should use authentic thinking when solving problems ${ }^{[9]}$. Thus, the students were free to use whatever resources - in whatever quantity they saw fit - in order to meet the module's deliverable.

\section{Student Performance Compared to a Non-Flipped Classroom}

With so much work being put into the schedule and development of assessments, an instructor might simply wonder if flipping the classroom is worth the effort. Although a direct comparison to a traditional classroom is difficult to make, given the increased amount of class time spent engaging with material and working on graded assessments, the author built this flipped classroom so that it could match a similar, non-flipped, version of the course as closely as possible. Analyzing the Fall 2013 (flipped) course against the Fall 2012 (non-flipped) course provides the closest comparison that could be made for this study. 
Both sections of the course used the same textbooks and course lectures (although face-to-face lectures were given in the classroom in the Fall 2012 non-flipped section.) The same case studies, deliverables, and final course projects were used. The courses were held on the same day and time and in the same classroom with the same instructor. Every effort was made to keep the course assessments and environment as similar as possible.

An independent-samples t test was calculated comparing the mean GPA of students in the 2012 and 2013 study course sections. The metric used was the students' cumulative GPA on a 4.0 scale upon the start of their semester in the study course. No significant difference in the GPA of the two classroom groups was found $(t(47)=.557, p>.05)$. The mean GPA of the 2012 students $(m=3.1490, s d=.49011)$ was not significantly different from the mean GPA of the 2013 students $(m=3.1395, s d=.45194)$.

As demonstrated in Figure 5, the Fall 2013 (flipped) course involved significantly more formative and interim assessments than before, but had a similar number of summative assessments (additional summative assessments were given in the flipped classroom section due to the introduction of a special project.)

The makeup of the final course grade was somewhat changed. Summative assessment, as referenced in Figure 6, comprised $66 \%$ of the total grade for the flipped classroom course, compared to $91 \%$ of the total grade for the non-flipped course. A comparison of the final student grades in the non-flipped and flipped courses appears in Figure 13.

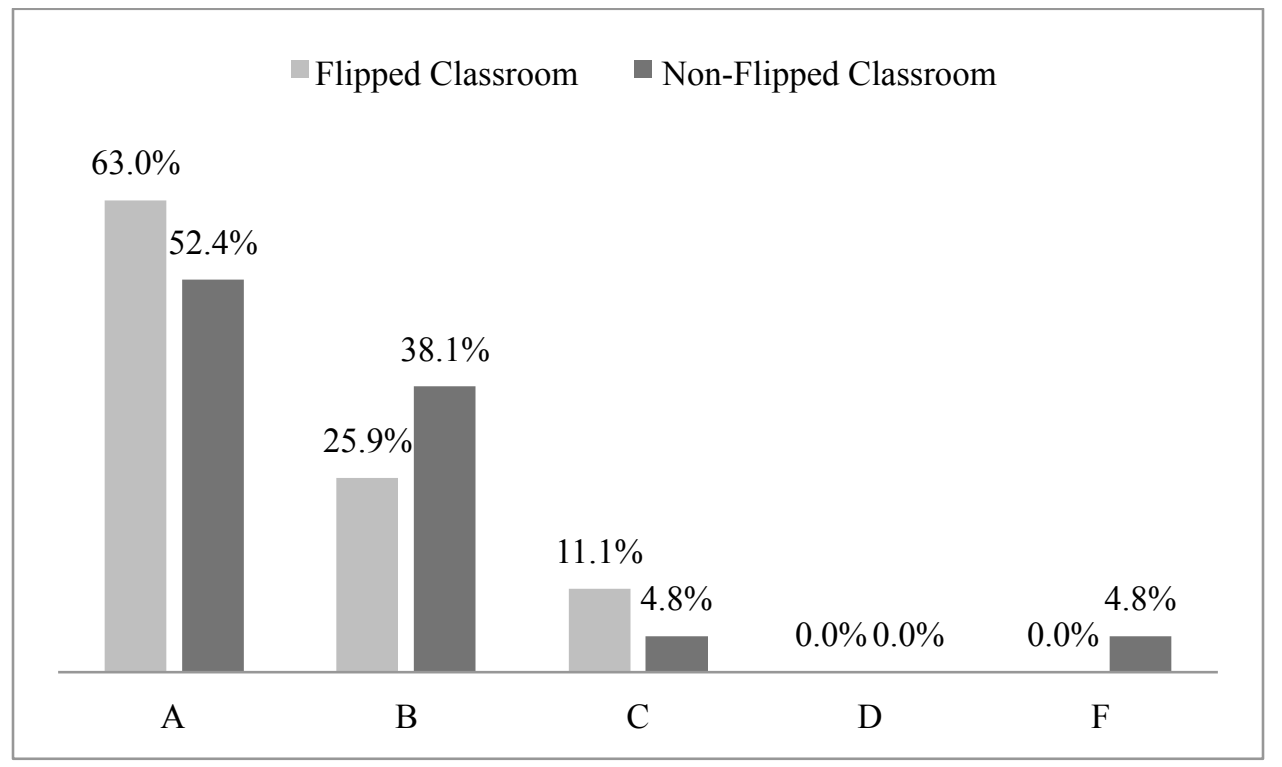

Figure 13: Grade Distribution Between Flipped $(n=27)$ and Non-Flipped $(n=21)$ Course Sections

Comparing the grade distribution of only summative assessments between the flipped and nonflipped courses might provide a more specific comparison, as shown in Figure 14. 


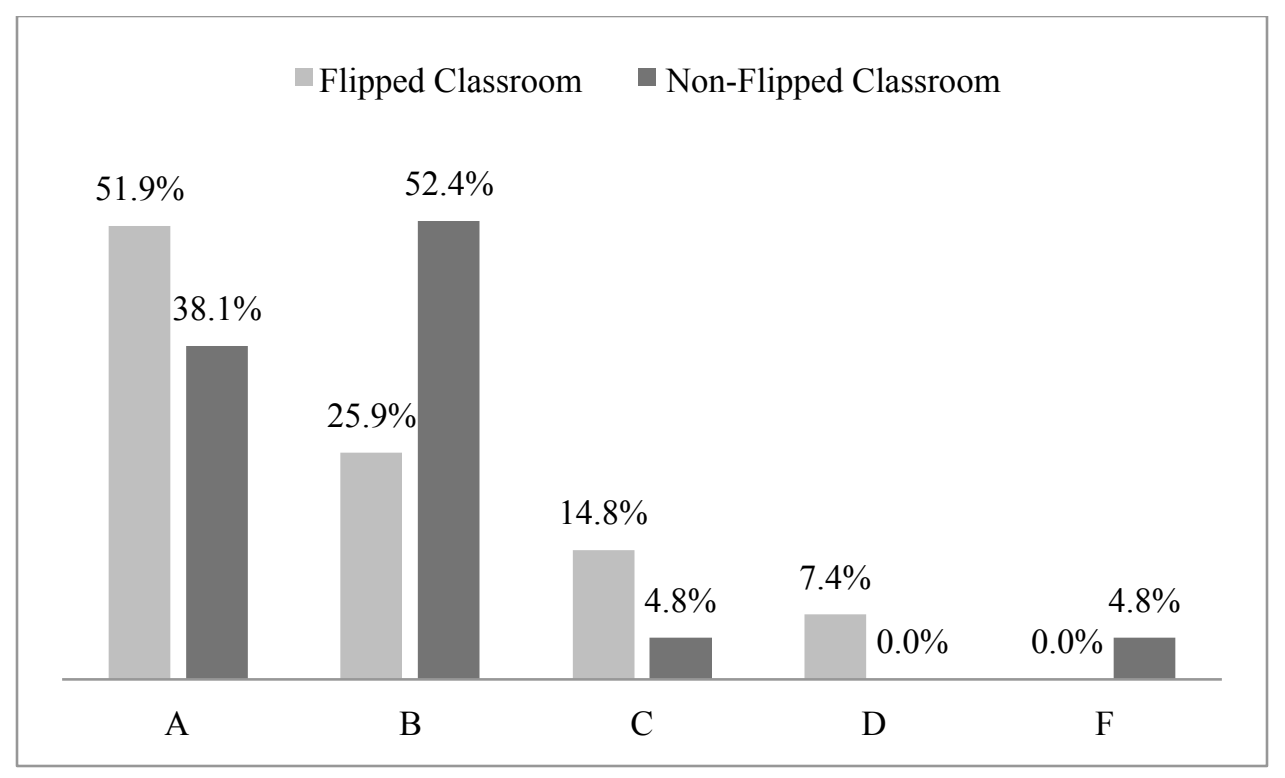

Figure 14: Grade Distribution of Summative Assessments Between the Flipped (n=27) and Non-Flipped (n=21) Course Sections

Although the grade distributions between the two course sections do differentiate, the average final course grades between the flipped section (89.3\%) and the non-flipped course section $(91.1 \%)$ are extremely similar. The median grade for the flipped classroom section (94.2\%) was higher than the non-flipped section $(91.2 \%)$, which indicates that there were more highly successful students in the flipped classroom section. While there does not appear to be a significant improvement in final grade outcomes for this course, this was a course with a very high average grade in the past. The flipped classroom pedagogy may have significantly more impact in a course with a lower average grade.

\section{Overall Satisfaction}

Although this implementation of the flipped classroom did not result in significantly improved final grades, the students did react well to the pedagogy. At the conclusion of the term students were asked for overall opinions about the flipped classroom. With the question "how satisfied were you with the flipped classroom pedagogy that was used this semester," the students were asked to give one of the following responses:

- Not at all satisfied (It impeded my learning.)

- Satisfied (It was an interesting experiment.)

- Very satisfied (I found it helpful.)

- Extremely satisfied (I want all of my classes flipped.) 


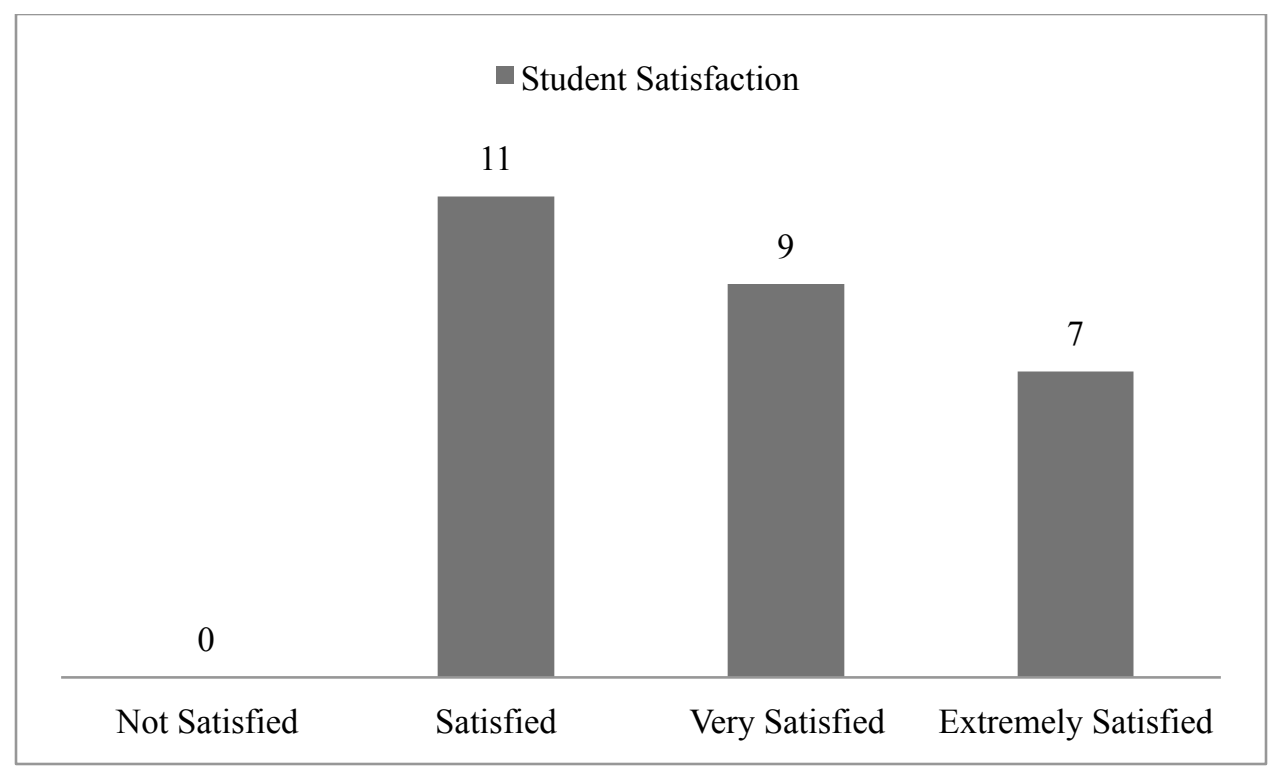

Figure 15: Student Satisfaction with the Flipped Classroom $(n=27)$

As no students noted that the flipped classroom was an impediment to learning, the author assumes that the flipped classroom is an acceptable, if not the preferred, methodology. In an attempt to get a more practical opinion, students were asked about their preference if they had the choice between a flipped and a non-flipped classroom section of an upcoming course. A majority of students $(56 \%)$ reported they would choose the flipped classroom section, while only $7 \%$ would choose a non-flipped section. These results are demonstrated in Figure 16.

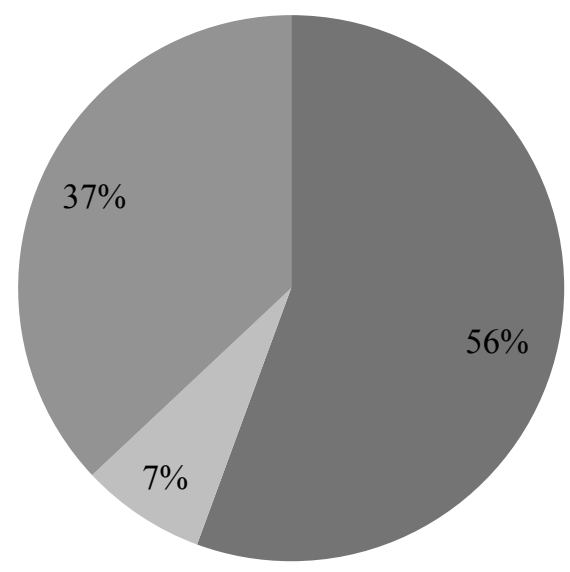

The flipped classroom section

The non-flipped classroom section

It wouldn't matter to me

Figure 16: Student Preference for Flipped vs. Non-Flipped Course Sections (n=27)

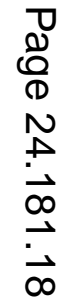


The students who enjoyed the flipped classroom were emphatic about it. A selection of student quotes appears below:

"Although it made the class seem very busy, I felt like I walked away from this class actually learning something. Some classes are not involved enough, and they let you slip by without actually learning anything new. The in-class exercises made sure you knew what was happening regardless of how much of the reading you did."

"The flipped classroom was a great idea that allows college students to be college students. They have the responsibility to be prepared for class which allows the teacher to then build on what they should have already learned or have an idea about, which removes lecturing, something students tend to ignore anyway."

"It was great! The video lectures were a great resource. Wish I had this in every class!" "I felt that the flipped classroom was very helpful and a lot better than taking the class online."

Students also provided some feedback toward improving the flipped classroom and its place in the curriculum:

"I really liked the flipped classroom, especially paired with my non-flipped classes. It helped even out my workload."

"Thursday was okay as a due date, but I didn't really like it. It would be better, for me at least, if due dates were a bit more consolidated."

"Didn't like the assignments being Thursday. Made it very difficult with my work schedule. In addition, did not think that missing class should effect [sic] my grade so much. If I do well in the class why should I be penalized due to unforeseen issues in my day that keeps me from class."

\section{Conclusion}

The flipped classroom pedagogy was applied to the Fall 2013 computer systems analysis and design course. The flipped classroom asks students to prepare for class by viewing recorded lectures and other course materials prior to coming to class, and then uses active and problembased learning techniques during class time to engage with the material the students had reviewed. The author intended to create a rich, collaborative learning environment and implemented the flipped classroom with four guiding principles in mind: 
1. Make it Fair to the Students

2. Balance the Course with Formative, Interim, and Summative Assessments

3. Make it Engaging for the Students

4. Focus on Outcomes, not on Inputs

The weekly structure of the course was shifted in an effort to afford students adequate preparation time for class. Formative and interim assessments were written so that they would specifically relate to the summative assessment for each learning module. Students used a variety of interactive assessments to demonstrate understanding of the material during class time. Finally, although some data was available to the instructor regarding the consumption of course materials (videos and readings), the author chose to allow students to engage with as much or as little of the material as they desired and instead focused on the application of the information from the course material.

By using anonymous surveys of students at the start, midpoint, and conclusion of the semester, it was determined that the students approached the flipped classroom with a bit of hesitation. However, they did respond that the adjusted schedule was fair, that the classroom activities were helpful and meaningful, that face-to-face time was engaging and peer collaboration was appropriate for the course, and that the flipped classroom structure might be preferable in other courses.

Although there was no significant improvement in the final course grades for this particular course when compared to a prior section's outcomes, the author and the students anecdotally reported increased vigor and interaction in the classroom. The flipped classroom provided a stimulating learning environment for students, who responded well to the pedagogy.

Recommendations for further study include an application of this flipped classroom pedagogy and survey materials to a course with a lower average grade to see if there is an improvement in the student outcomes. Also of interest would be an examination of the retention of material from the flipped classroom course in subsequent courses that build on the material learned earlier in the curriculum.

\section{References}

1. Lage, M.J., G.J. Platt, and M. Treglia, Inverting the Classroom: A Gateway to Creating an Inclusive Learning Environment. Journal of Economic Education, 2000. 31(1): p. 30-43.

2. Roehl, A., S.L. Reddy, and G.J. Shannon, The Flipped Classroom: An Opportunity To Engage Millennial Students Through Active Learning. Journal of Family and Consumer Sciences, 2013. 105(2): p. 44-49.

3. Bishop, J.L. and M.A. Verleger. The Flipped Classroom: A Survey of the Research. in 2013 ASEE Annual Conference. 2013. Atlanta, GA: American Society for Engineering Education.

4. Zappe, S., et al. "Flipping" the classroom to explore active learning in a large undergraduate course. in American Society for Engineering Education Annual Conference and Exposition. 2009. Austin, TX. 
5. Gannod, G.C., J.E. Burge, and M.T. Helmick, Using the inverted classroom to teach software engineering, in Proceedings of the 30th international conference on Software engineering2008, ACM: Leipzig, Germany. p. 777-786.

6. Grabinger, R.S. and J. Dunlap, Rich environments for active learning: A definition. Association for Learning Technology Journal, 1995. 3(2): p. 29.

7. Davis, K., L. Gillette, and J.R. Gillette, How to Ensure that Students Prepare for Class So That Class Time Can Be Used for Deep Learning, in Lilly International Conference on College Teaching2013: Oxford, Ohio.

8. Toto, R. and H. Nguyen, Flipping the work design in an industrial engineering course, in Proceedings of the 39th IEEE international conference on Frontiers in education conference2009, IEEE Press: San Antonio, Texas, USA. p. 1066-1069.

9. Savery, J.R. and T.M. Duffy, Problem Based Learning: An instructional model and its constructivist framework. Educational Technology, 1995(35): p. 31-38. 